\title{
C-reactive Protein (CRP) as Diagnostic Marker of Pneumonia in Children
}

\author{
Iffat $\mathrm{Naz}^{1 *}$ \\ ${ }^{1}$ Department of Biology, Scientific Unit, Deanship of Educational Services, Qassim University, Buraidah, 51452, Qassim,
} Kingdom of Saudi Arabia (KSA)

\begin{abstract}
Pneumonia is an inflammation of the lung parenchyma tissue that mainly affects the respiratory bronchioles and alveoli. The present research study is focused on assessment of the C-reactive protein (CRP) test as a tool marker for the diagnosis of pneumonia among children. In the current study, a total of 450 patients admitted to the children ward at Lady Reading Hospital (LRH) Peshawar, Khyber Pakhtunkhwa, Pakistan were selected, out of which 55\% were male and $45 \%$ were female. In addition, two groups were designed according to age i.e. 1-8 years and 9-16 years of age with a frequency of 55 and $45 \%$, respectively. In case of chest X-ray assessment, it was observed that all patients were highly susceptible to pneumonia infection, while from blood culture analysis, it was perceived that 419 patients (93\%) were highly susceptible to pneumonia infection. Two bacterial isolates (Klebsiella pneumoniae and Streptococcus pneumoniae) were characterised from all positive samples. In contrast with CRP assessment, 385 patients (85\%) had positive CRP reports displaying more than $5 \mathrm{mg} / \mathrm{L} \mathrm{CRP}$ values and 65 patients (15\%) had negative CRP reports. Thus, it was concluded that patients with high CRP values presented clear evidence of a severe infection. Moreover, it is suggested that CRP is a sensitive, less time consuming and inexpensive technique; therefore, it has been recommended to be used as a tool marker along with other diagnostic techniques for the diagnosis of life-threaten infections to get a more clear picture about infections.
\end{abstract}

Keywords: pneumonia; pathogenic bacteria; chest X-ray; culturing; CRP test

\section{INTRODUCTION}

Pneumonia is an inflammatory state of the lungs parenchyma that mainly affects the microscopic air sacs, respiratory bronchioles, and alveoli (Schuetz et al., 2011). The most common signs and symptoms are seen in patients suffering from pneumonia includes difficulty in breathing, fever, chest indrawing, chest pain, and bilateral crept (Bratzler et al., 2013). The World Health Organization (WHO) has defined pneumonia as a state of illness, having one of the following signs and symptoms, i.e. difficulty in breathing (central cyanosis or saturation less than 90\%) and dry or productive cough (UNICEF WHO, 2019). Most common cause of pneumonia is either viruses or bacteria or other microorganisms. In the majority of the cases, S. pneumoniae,
S. aureus, $H$ influenza $\mathrm{B}$, and certain viruses are involved (Hopstaken et al., 2016).

Pneumonia is a considerable reason for mortality in children throughout the world, especially in developing countries such as India, Nepal, Bangladesh, and Pakistan. In addition, pneumonia has been considered as a fatal disease for the children because $29 \%$ of deaths of children at the age of 3-5 years were recorded throughout the world due to pneumonia (Madhi et al., 2013). Further, it has been evaluated that around $10-15 \%$ of children with pneumonia will require hospitalization frequently due to severe complications (Slinger et. al., 2014; UNICEF WHO, 2019). Previous reports have shown a high pneumonia rate in South East Asia (Hasan et al., 2014), while the bulletin of the UNICEF WHO (2019) inferred that "An extensive and precise depiction of the study of disease transmission and etiology of 
adolescence pneumonia is a fundamental initial step for the avoidance and administration of disease". Polymerase Chain Reaction (PCR) and culturing techniques are often used for the assimilation of the causative agent of pneumonia. It has been reported that in developing countries, more than $85 \%$ causalities of children occurred due to pneumonia (Hasan et. al., 2014; UNICEF WHO, 2019). Therefore, there is a need to investigate simple, reasonably inexpensive, and sensitive techniques for the diagnosis of pneumonia in children of different age groups (O’Callaghan-Gordo et al., 2011). Recently, C-reactive protein (CRP) has been used as a tool marker for the examination and finding of pneumonia in developing countries because of its quick response towards the diagnosis of infection (Schouten et. al., 2016; Mani, 2018). CRP is a pentameric protein found in blood plasma, and its level rises in response to inflammation. Nowadays it has been used as a blood test marker to determine the levels of inflammation within the body (Black et. al., 2010; Kim et. al., 2016; Tate et al., 2016). The CRP evaluation is done by obtaining a blood sample from the vein of the patient and then its level is investigated through CRP latex test kits. Thus, the CRP act as an indicator of the presence of some inflammation inside the body (Muller et. al., 2010; Kaysin et. al., 2016; Klouche et al., 2016). It is an initial but nonspecific acute-phase inflammatory biomarker. The main biological role of CRP is the activation of the complement system and other pro-inflammatory processes of cytokines. In healthy people, the normal level of CRP is $0.8 \mathrm{mg} / \mathrm{L}$, but as a result of an acute-phase stimulation due to infection, the CRP level can increase to 500-10,000 mg/L (Tate et al., 2016).

Nowadays in clinical practice, the CRP is widely used to diagnose various diseases and level of inflammation by checking their level in blood serum. Regardless of its low specific nature, CRP is often used because it is a very sensitive marker for inflammatory processes or tissue damage. It is also conducted for checking the progress of a disease and its treatment outcome and also for the diagnosis of inflammatory responses. Moreover, CRP is a highly sensitive, less time consuming and inexpensive technique that is why it is widely employed in clinical practices. The current research study is mainly focused on the assessment of CRP as a tool marker in the diagnosis of pneumonia among children in district Peshawar, Pakistan.

\section{MATERIALS AND METHODS}

This study was conducted after approval from the hospitals ethical and research committee. All children admitted in the children ward at Lady Reading Hospital, Peshawar, Pakistan with high suspicious of pneumonia were included in the study. The purpose of the study was explained to the parents of the children; they were assured of the benefits of the study, the risks involved and they were also assured that the study was conducted purely for research and data publication. All children were subjected to detailed clinical examination and brief history was obtained from their parents (Annexed-I). All the parents were agreed and cooperated in providing the clinical details of their child.

\section{A. Inclusion Criteria}

All children must be suspected with chest infection having signs and symptoms of pneumonia, and also must be in the age range of 1-16 years (both male and female gender).

\section{B. Exclusion Criteria}

Patients with history of surgical intervention such as abdominal, cardiac or renal surgery were excluded from the research study.

\section{Sample Collection}

A total of 450 blood samples were collected from all children admitted in the children ward at Lady Reading Hospital, Peshawar, Pakistan, with high suspicion of pneumonia based on signs and symptoms. In addition, two groups of patients were designed according to age i.e. 1-8 years and 9-16 years of age with the frequency of $55 \%(n=250)$ and $45 \%(n=$ 200), respectively. About 5 cc of blood was obtained under strict aseptic conditions from each patient and was then sent to the hospital laboratory immediately to detect inflammatory responses towards pneumonia on the basis of CRP level. The same blood specimen was also transferred for complete blood culture analysis in the same hospital laboratory to confirm the causative agent for pneumonia and in the meantime, a chest X-ray was also performed.

\section{Assessment of Chest X-ray}

Pneumonia is diagnosed on the basis of X-ray findings in the form of a whitish patch called pneumonic patch. Air on chest 
X-ray looks black (radiolucent) and inflammation due to pneumonia gives a whitish radio-opaque shadow. If it is confined to a single lobe then it is called lobar pneumonia. In the X-ray film air-ways, bony shadows, cardiac shadow, diaphragm and angles of a diaphragm with heart and ribs, equal volumes fluids (pleural effusion) and gastric shadows should be checked to find out other abnormalities or complications of pneumonia in the form of para-pneumonic effusion or hyperinflation of the lungs.

In the current research study, all the patients who fulfilled the inclusion criteria and clinical signs and symptoms were first sent for chest X-ray examination. In a condition, if a radio-opaque shadow on the right or left side called consolidation or haziness was observed and if it covered the entire lobe, then it was called as lobar pneumonia. If the consolidation or haziness was bilateral and diffuse, then it was called as broncho-pneumonia (either involves both lungs or cover one lobe of the right and left lung).

\section{E. Assessment of C - Reactive Protein (CRP) Assay}

For CRP analysis, C-reactive protein (CRP) latex test kits (Aspen Laboratories 7 A, HPSIDC Ind, Area, Baddi, H.P.) were used. About 1-2 mL of blood was taken from the patients using a sterile syringe, then it was transferred into the gel bottle and this gel bottle was labelled with patient's code name, age, ward number and bed number. The blood sample of each sample was centrifuged at 5000 rpm for 4-5 minutes. After centrifugation, plasma was separated from the red blood cells and appeared on the top in as a transparent liquid. In the kit, three bottles were used, which represent positive control, latex CRP and negative control. On a glass slide, three drops of latex CRP were added in a row. After this, $0.5 \mu \mathrm{l}$ of positive and negative controls were added to the 1st and 2nd drop, respectively and then mixed with the help of a sterilized disposable stick. With positive control, agglutination occurred while with negative control, no agglutination would take place. After that, $0.5 \mu \mathrm{l}$ of blood serum was added to the 3rd drop with a micropipette P10 and then mixed with a disposable stick. After a few minutes, the reaction in the 3 rd drop was compared with the reaction of the positive and negative control. If agglutination occurs, then this means the CRP level of the tested blood sample is above $5 \mathrm{mg} / \mathrm{L}$ and indicates a positive CRP test.

\section{F. Assessment of Blood Culture Assay}

About 5 cc of blood was taken from each patient under strict aseptic condition and then transferred into $30 \mathrm{~mL}$ media culture bottle. Then it was incubated at $37^{\circ} \mathrm{C}$ for two to three days in an incubator. After incubation, it was inoculated on blood agar and chocolate agar media plates. These media were prepared according to the instructions of the manufacturer and sterilized by autoclaving at $121^{\circ} \mathrm{C}$ for 15 minutes at $15 \mathrm{lbs}$./inch2 (psi) pressure. About 15-20 mL of media was poured in each plate with half lid open and was then left to solidify for one day. To check the sterility, the prepared media was incubated overnight at $37^{\circ} \mathrm{C}$. After the media has solidified, one drop of the sample from the culture bottle was added to the blood agar and chocolate agar plate. It was then streak and labelled the plate with patient's ID and left it for 3-4 days. After 3-4 days, the appearance of growth on plates was indicative of positive culture. If no growth appears then it would be considered as negative culture. Then further confirmation of bacteria from positive samples were done through pure culturing technique, i.e. determining the morphology of the test organisms in culture plates, microscopic analysis and biochemical tests according to Holt et al. (1994).

\section{RESULTS}

\section{A. Frequency Distribution of Test Subjects}

In the current study, total 450 patients were selected on the basis of their severe clinical conditions. Moreover, all these patients were admitted in the Children ward of LRH, Peshawar, Pakistan and fulfilled the inclusion and exclusion criteria which were included in the study. Further, all the patients were distributed into two groups according to their age, i.e. the first group included patients of 1-8 years of age and the second group included the patients of 9-16 years of age. Among 450 patients, the frequency distribution in the first group was 250 (55\%), and in the second group were 200 (45\%) as shown in Figure 1. In addition to this, all the patients who were susceptible to pneumonia were also categorized again into two groups on the basis of gender. It was observed that $55 \%$ (250 patients) were from the male group and $45 \%$ (200 patients) were females as shown in the Figure 2. 


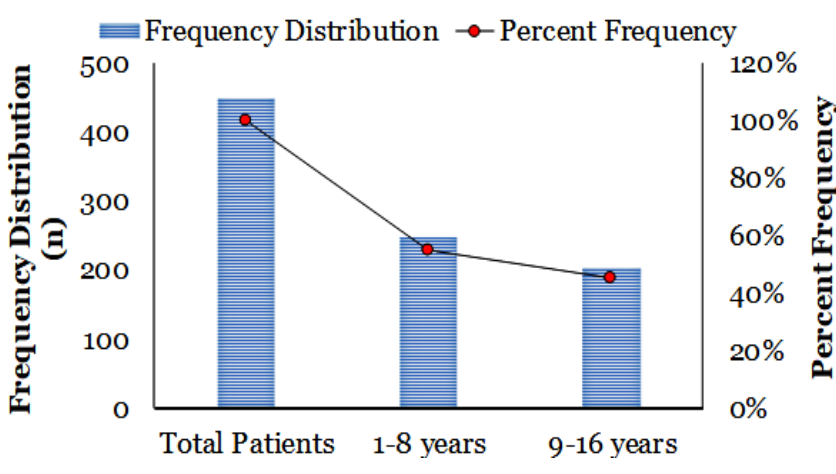

Figure 1. Age-wise frequency distribution of patients

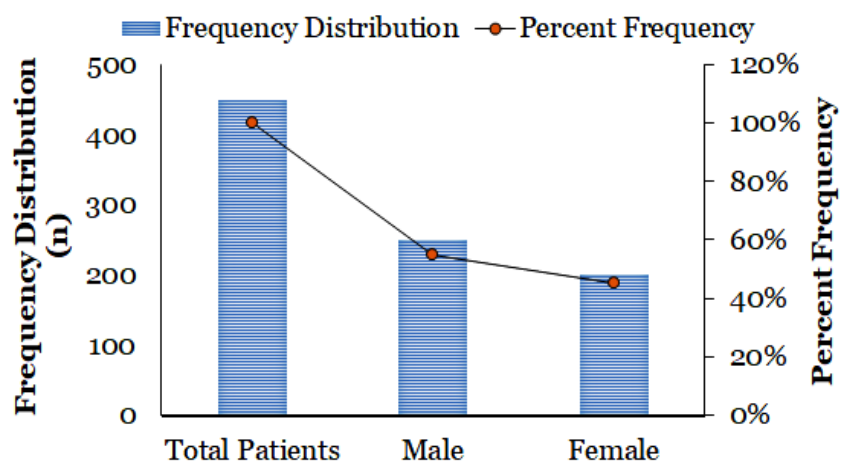

Figure 2. Gender-wise frequency distribution of patients

\section{B. Assessment of Chest X-ray}

In the case of chest X-ray assessment, it was observed that all 450 patients (including patients of both age groups) had positive chest X-ray reports (100\%), showing that all were highly susceptible to pneumonia infection as shown in Figure 3.

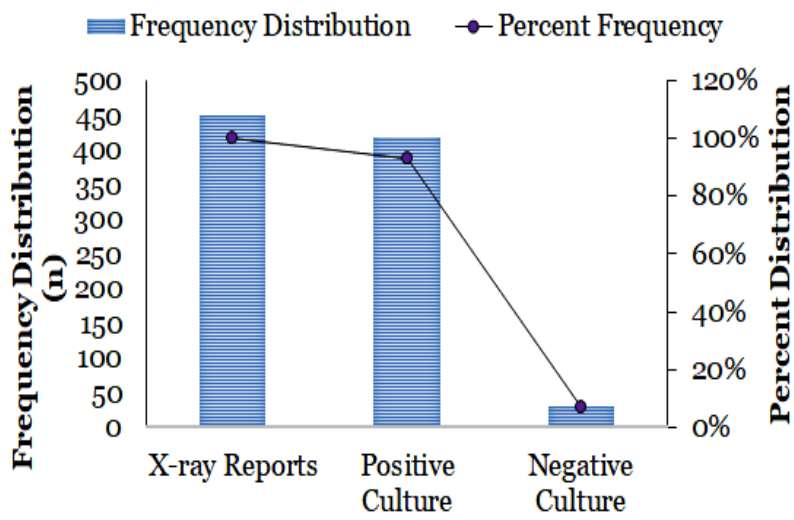

Figure 3. Assessment of chest X-ray and blood culture (positive and negative) tests

\section{Blood Culture Analysis}

In blood culture analysis, it was observed that 419 patients (93\%) out of 450 patients were highly susceptible to pneumonia infection; therefore they had positive blood culture reports while 31 patients (7\%) out of 450 had negative blood culture reports as shown in Figure 3. Further, two different bacterial isolates from positive blood culture samples were characterized according to Holt et al. (1994). It was observed that isolate \# 01 was Gram negative, have pink colour rods with scattered arrangement. While isolate \# 2 was Gram positive, purple colour lancelets shaped diplococci under a microscope as shown in Figure 4. After microscopy, these bacterial isolates were sub-cultured on different culture media and different cultural characteristics were observed. After cultural characteristics, complete identification of these bacterial isolates were carried out by performing different biochemical tests, i.e. carbohydrate fermentation, citrate test, urease test, catalase test and triple sugar iron test. The detail description of cultural characteristics and biochemical analyses of bacterial isolates is given in Table 1 and 2.
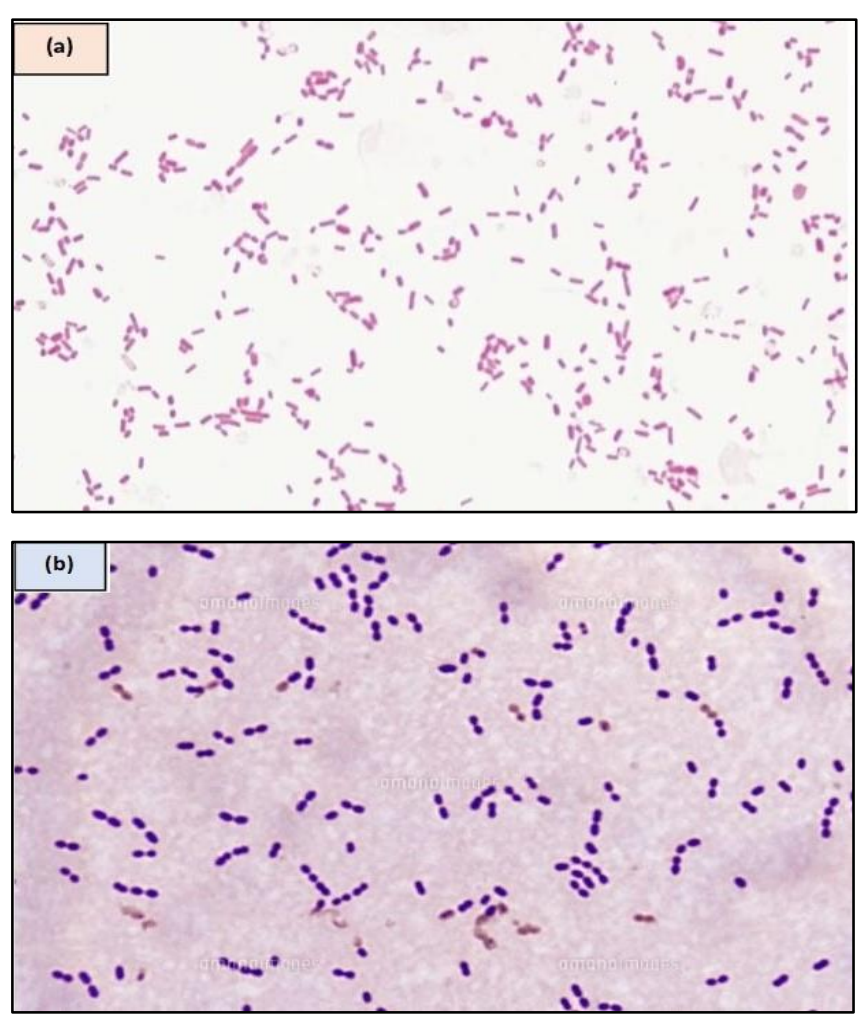

Figure 4. Microscopic images of isolated bacteria from positive culture samples (a) K. pneumoniae and (b) $S$. pneumoniae 
Table 1. Cultural characteristics of isolated bacteria on different media

\begin{tabular}{|c|c|c|c|c|c|c|c|c|c|c|c|c|}
\hline \multirow{2}{*}{\multicolumn{2}{|c|}{ Isolates }} & \multicolumn{11}{|c|}{ Cultural Characteristics on different media } \\
\hline & & \multicolumn{3}{|c|}{ NA } & \multicolumn{3}{|c|}{ EMB } & & \multicolumn{2}{|c|}{ SS } & & $\overline{\mathbf{B A}}$ \\
\hline \multicolumn{2}{|c|}{1} & \multicolumn{3}{|c|}{$\begin{array}{l}\text { Slimy white, translucent, } \\
\text { convex mucoid }\end{array}$} & \multicolumn{3}{|c|}{$\begin{array}{l}\text { Purple dark } \\
\text { central mucoid } \\
\text { colony }\end{array}$} & \multicolumn{3}{|c|}{$\begin{array}{l}\text { White slimy, shiny } \\
\text { appearance }\end{array}$} & \multicolumn{2}{|r|}{ N.S } \\
\hline \multicolumn{2}{|c|}{2} & \multicolumn{3}{|c|}{$\begin{array}{l}\text { Abundant, opaque, white } \\
\text { waxy growth }\end{array}$} & \multicolumn{3}{|c|}{ N.S } & \multicolumn{3}{|c|}{ N.S } & \multicolumn{2}{|c|}{$\begin{array}{l}\text { Good growth, } \alpha- \\
\text { hemolysis }\end{array}$} \\
\hline \multicolumn{13}{|c|}{$\begin{array}{l}\text { Key: NA = Nutrient agar; EMB = Eoisen methylene blue agar; SS = Salmonella-shigella agar; BA = Blood agar; N.S = No } \\
\text { streak }\end{array}$} \\
\hline \multicolumn{13}{|c|}{ Table 2. Biochemical tests of isolated bacteria } \\
\hline & \multicolumn{3}{|c|}{ Fermentation } & & & & & & & & \multirow[b]{2}{*}{ 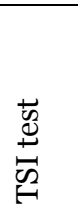 } & \multirow[b]{2}{*}{$\begin{array}{l}\text { Identified } \\
\text { Organisms }\end{array}$} \\
\hline 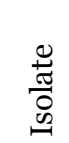 & 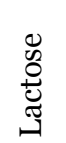 & 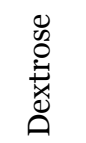 & 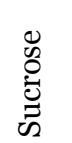 & $\begin{array}{l}\frac{2}{w 2} \\
\frac{2}{0} \\
\stackrel{0}{0} \\
\stackrel{1}{1}\end{array}$ & 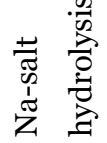 & 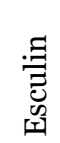 & $\begin{array}{l}\frac{2}{2} \\
\frac{2}{0} \\
\stackrel{0}{0}\end{array}$ & 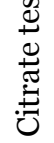 & 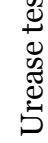 & 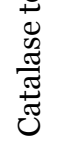 & & \\
\hline 1 & $\mathrm{AG}$ & AG & $\mathrm{AG}$ & - & - & + & + & + & + & + & $\mathrm{A} / \mathrm{A}$ & K. pneumoniae \\
\hline 2 & - & - & - & $\overline{\mathrm{A}}$ & \pm & 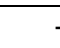 & 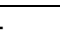 & \pm & - & + & $\mathrm{A} / \mathrm{A}$ & S. pneumoniae \\
\hline
\end{tabular}

Key: AG = Acid and gas; + = Positive; - = Negative; \pm = Variable reaction; A/A = Acidic reaction both in the Slant/Butt region

\section{Assessment of CRP}

In the case of CRP assessment, it was summarized that overall 385 patients $(85 \%)$ out of 450 patients had positive CRP reports showing that the CRP level was above $5 \mathrm{mg} / \mathrm{L}$, while 65 patients (15\%) out of 450 patients had negative CRP reports demonstrating that CRP level was less than $5 \mathrm{mg} / \mathrm{L}$ as shown in Figure 5. Further, it was observed that out of 250 patients in the age group of 1-8 years, 214 patients (85.6\%) had positive and 36 patients (14.4\%) had negative CRP reports. While out of 200 patients in the age group of 9-16 years, 171 patients $(85.5 \%)$ had positive and 29 patients (14.5\%) had negative CRP reports (Annexed-II).

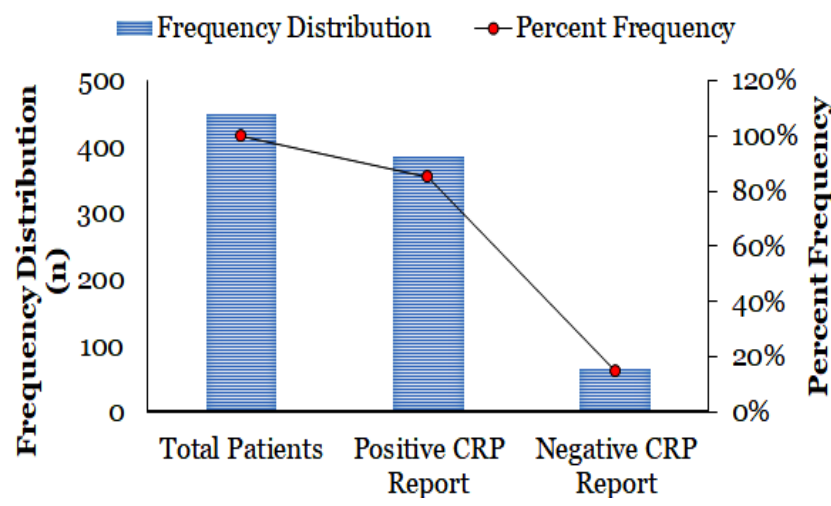

Figure 5. Assessment of CRP test to diagnose pneumonia among patients

\section{DISCUSSION}

Over the past two decades, a significant improvement had been observed in the living standard of people of developing and underdeveloped countries with respect to social and economic perspective, as a result a substantial reduction has been found in the emergence of respiratory infections such as pneumonia, tuberculosis etc. (Ibrahim et. al., 2017; Stein et al., 2017). However, the morbidity and death rates of pneumonia infection among children remain high in the majority of developing countries like Pakistan, India, Bangladesh and Nepal (Rudan et al., 2013). According to UNICEF WHO (2019) reports, "pneumonia accounts for $15 \%$ of all deaths of children under 5 years age, and killed 0.8 million children in the developing countries in 2017". Pneumonia has been considered as a fatal disease for the children because $29 \%$ of deaths of children at the age of 3-5 years were recorded throughout the world due to pneumonia (Madhi et al., 2013). A basic reason for this high incidence rate of pneumonia among children in developing countries is unhygienic environment, lack of facilities to provide proper up-to-date early diagnosis level and treatment (Schuetz et. al., 2009; Vogelmeier et al., 2017).

The diagnosis of pneumonia is based on clinical manifestation of the disease and prompt treatment. Certain 
investigations are used to determine or confirm the diagnosis of pneumonia, i.e. arterial and venous blood gases and oxygen saturation (central venous oxygen saturation), Full Blood Count (FBC), serum sugar, and serum lactate level (Phua et. al., 2016; Cilloniz et al., 2018). A pure culturing technique is applied to confirm the causative agent and then proper antibiotic treatment has been started for the management of the disease (Karakioulaki \& Stolz, 2019). In primary healthcare facilities, physicians count on patient's clinical history and physical condition (Chalmers, 2016). Further, it has been reported in clinical practices that several factors such as chest $\mathrm{X}$-ray, blood culturing and CRP tests must be considered because clinical signs and symptoms alone are not enough to investigate pneumonia (Maisel et al., 2012).

According to the WHO endorsed treatment plan for severe pneumonia, including supportive care, appropriate immunotherapy and intensive care treatment should be managed timely in order to reduce the death rate (Chalmers et. al., 2011; Maisel et. al., 2012; Karakioulaki \& Stolz 2019). While, CRP is an initial but nonspecific acute-phase inflammatory biomarker (Chalmers et al., 2011). In response to any inflammation inside the body, the body CRP level rise and the test of CRP is also advised when pneumonia is suspected in the patient. Because raised CRP values are usually found in pneumonia, and a high CRP value is shown to be a strong indicator for pneumonia in general practice. However, raised CRP values may also be found in uncomplicated viral respiratory infections but they don't go as high as during bacterial infection (Self et al., 2017). Further, CRP is a general biomarker and shows that there is some inflammation in the body tissue. The main biological role of CRP is activation of the complement system and of other proinflammatory processes of cytokines. Previous studies reported the diagnostic significance of CRP in relation to pneumonia, while further studies specified that CRP was associated with disease severity and mortality in hospitalized patients (Lee et. al., 2011; Diez-Padrisa et. al., 2012; Kolditz et al., 2012).

The present research study was focused on the assessment of CRP as a tool marker for the diagnosis of pneumonia among children in Peshawar, Pakistan. In the current study, a total of 450 patients was selected based on their severe clinical condition. Moreover, all these patients were admitted to the children ward at LRH, Peshawar, Pakistan, and fulfilled the inclusion and exclusion criteria were included in the study. All children were subjected to detailed clinical examination and brief history was obtained from their parents. Besides CRP assessment, chest X-ray and blood culturing tests were also performed. In the case of CRP assessment, it was observed that 385 patients (85\%) out of 450 patients had positive CRP reports showing that the CRP level was above $5 \mathrm{mg} / \mathrm{L}$, while 65 patients (15\%) had negative CRP reports. In the case of chest x-ray, it was observed that all 450 patients had positive chest X-ray reports (100\%) showing that all were highly susceptible to pneumonia infection, while in the case of blood culturing, it was observed that $93 \%$ patients showed positive bacterial culture and $7 \%$ displayed negative blood culture reports. Further, two different bacterial isolates, i.e. $S$. pneumoniae and $K$. pneumoniae have been identified from the positive blood culture samples. The current study have similarities with the previous research conducted by Turner et al. (2013). They reported that bacterial infections (Pneumococcus, hemolytic Streptococci and Haemophilus species) were major causes of pneumonia, particularly of severe pneumonia among children and CRP gave positive response towards the severity of infection.

The diagnosis of severe pneumonia in children from the number of developing countries is limited due to the lack of X-ray facilities. In addition, the diagnosis depends on clinical indications, and therapy mainly depends on empirical treatment (Schwarz et al., 2010). A diagnosis based on clinical distrust and local clinical experience tends to delay treatment and result in severe consequences (Ten Oever et al., 2016). The most important and dignified reasons for treatment failure are long term therapy, excessive usage of medication, especially antibiotics and disobey WHO suggested treatment plan for pneumonia infection (Wiersinga et. al., 2016; Varon et al., 2019). Thus, several challenges remain in the initial diagnosis of severe pneumonia among children. The current guidelines for diagnosis are based on clinical signs and symptoms, which makes a rapid diagnosis in children extremely important for a positive clinical outcome. Further, in the current study, it has been concluded that CRP is an accurate and sensitive technique to be used apart from clinical signs and symptoms, 
chest X-ray and blood culturing techniques for the diagnosis of pneumonia.

\section{CONCLUSIONS}

It was concluded from the current research, that CRP quantification could be of additional value in diagnosing pneumonia from other available techniques. High values of CRP (85\%) along with pneumonia signs and symptoms showed that children admitted in the children ward at LRH, Peshawar, Pakistan were at high risk; therefore, proper treatment would be started for pneumonia without awaiting the results of chest X-ray and blood culturing. The blood culture sensitivity test takes 3-7 days and pneumonia infection in severe condition can cause death especially in children. Thus, by keeping in mind the signs and symptoms of pneumonia, the chest X-ray and CRP test can be conducted in a short time for prompt initiation of antibiotic therapy. Therefore, a potential study regarding CRP assessment in all hospital settings would be warranted.

\section{ACKNOWLEDGEMENTS}

I am so much thankful to Miss. Zara Kamran (M. Phil Scholars), for assisting in the collection of blood samples of all admitted patients in the children ward at LRH, Peshawar, Pakistan. I am grateful to Dr. Abdul Rehman for providing me laboratory facilities, at the Department of Microbiology \& Biotechnology, Abasyn University Peshawar, Pakistan. Further, I can't forget to thank Dr. Saleh S Alhewairini, Dean of Deanship of Educational services, Qassim University, KSA for allowing me to conduct my research activities smoothly.

\section{REFERENCES}

Black, RE, Cousens, S, Johnson, HL, Lawn, JE, Rudan, I, Bassani, DG, Jha, P, Campbell, H, Walker, CF, Cibulskis, R \& Eisele, T 2010, 'Global, regional, and national causes of child mortality in 2008: a systematic analysis', The Lancet, vol. 375, no. 9730, pp. 1969-1987.

Bratzler, DW, Dellinger, EP, Olsen, KM, Perl, TM, Auwaerter, PG, Bolon, MK, Fish, DN, Napolitano, LM, Sawyer, RG, Slain, D \& Steinberg, JP 2013, 'Clinical practice guidelines for antimicrobial prophylaxis in surgery', Surgical Infections, vol. 14, no. 1, pp. 73-156.

Chalmers, JD 2016, 'The modern diagnostic approach to community-acquired pneumonia in adults', in Seminars in Respiratory and Critical Care Medicine, Thieme Medical Publishers, vol. 37, no. 06, pp. 876-885.

Chalmers, JD, Mandal, P, Singanayagam, A, Akram, AR, Choudhury, G, Short, PM \& Hill, AT 2011, 'Severity assessment tools to guide ICU admission in communityacquired pneumonia: systematic review and meta-analysis', Intensive Care Medicine, vol. 37, no. 9, pp. 1409.

Cillóniz, C, Liapikou, A, Martin-Loeches, I, Garcia-Vidal, C, Gabarrús, A, Ceccato, A \& Torres, A 2018, 'Twenty-year trend in mortality among hospitalized patients with pneumococcal community-acquired pneumonia', PloS One, vo. 13 , no. 7 , pp. e0200504.
Hasan, R, Rhodes, J, Thamthitiwat, S, Olsen, SJ, Prapasiri, P, Naorat, S \& Sawatwong, P 2014, 'Incidence and etiology of acute lower respiratory tract infections in hospitalized children younger than 5 years in rural Thailand', The Pediatric Infectious Disease Journal, vol. 33, no. 2, pp. 45.

Holt, JG, Krieg, NR \& Sneath, PH 1994, Bergey's manual of determinative bacteriology, 9th edn, Baltimor: William \& Wilkins, Maryland, US.

Hopstaken, R \& Harmans, L 2016, Pointofcare testing for Creactive protein, A Practical Guide to Global Point-of-Care Testing, CSIRO Publishing, Melbourne, Australia.

Ibrahim, MK, Zambruni, M, Melby, CL \& Melby, PC 2017, 'Impact of childhood malnutrition on host defense and infection', Clinical Microbiology Reviews, vol. 30, no. 4, pp. 919-971.

Karakioulaki, M \& Stolz, D 2019,'Biomarkers and clinical scoring systems in community-acquired pneumonia', Annals Of Thoracic Medicine, vol. 14, no. 3, pp. 165.

Kaysin, A \& Viera, AJ 2016, 'Community-acquired pneumonia in adults: diagnosis and management', American Family Physician, vol. 94, no. 9, pp. 698-706.

Kim, L, McGee, L, Tomczyk, S \& Beall, B 2016, 'Biological and epidemiological features of antibiotic-resistant Streptococcus pneumoniae in pre-and post-conjugate 
vaccine eras: a United States perspective', Clinical Microbiology Reviews, vol. 29, no. 3, pp. 525-552.

Klouche, K, Cristol, JP, Devin, J, Gilles, V, Kuster, N, Larcher, R \& Dupuy, AM 2016, 'Diagnostic and prognostic value of soluble CD14 subtype (Presepsin) for sepsis and community-acquired pneumonia in ICU patients', Annals of Intensive Care, vol. 6, no. 1, pp. 59.

Kolditz, M, Höffken, G, Martus, P, Rohde, G, Schütte, H, Bals, R \& Pletz, MW 2012, 'Serum cortisol predicts death and critical disease independently of CRB-65 score in community-acquired pneumonia: a prospective observational cohort study', BMC Infectious Diseases, vol. 12, no. 1, pp. 90.

Lee, JH, Kim, J, Kim, K, Jo, YH, Rhee, J, Kim, TY \& Hwang, SS 2011, 'Albumin and C-reactive protein have prognostic significance in patients with community-acquired pneumonia', Journal of Critical Care, vol. 26, no. 3, pp. 287294.

Madhi, SA, De Wals, P, Grijalva, CG, Grimwood, K, Grossman, R, Ishiwada, N \& Vergison, A 2013, 'The burden of childhood pneumonia in the developed world: a review of the literature', The Pediatric Infectious Disease Journal, vol. 32, no. 3, pp. e119-e127.

Maisel, A, Neath, SX, Landsberg, J, Mueller, C, Nowak, RM, Peacock, WF \& Richards, M 2012, 'Use of procalcitonin for the diagnosis of pneumonia in patients presenting with a chief complaint of dyspnoea: results from the $\mathrm{BACH}$ (Biomarkers in Acute Heart Failure) trial', European Journal Of Heart Failure, vol. 14, no. 3, pp. 278-286.

Mani, CS 2018, 'Acute pneumonia and its complications', Principles and Practice of Pediatric Infectious Diseases, pp. 238.

Müller, F, Christ-Crain, M, Bregenzer, T, Krause, M, Zimmerli, W, Mueller, B \& Schuetz, P 2010, 'Procalcitonin levels predict bacteremia in patients with communityacquired pneumonia: a prospective cohort trial', CHEST Journal, vol. 138, no. 1, pp. 121-129.

O'Callaghan-Gordo, C, Bassat, Q, Morais, L, Díez-Padrisa, N, Machevo, S, Nhampossa, T \& Roca, A 2011, 'Etiology and epidemiology of viral pneumonia among hospitalized children in rural Mozambique: a malaria endemic area with high prevalence of human immunodeficiency virus,' The Pediatric Infectious Disease Journal, vol. 30, no. 1, pp. 3944.

Phua, J, Dean, NC, Guo, Q, Kuan, WS, Lim, HF \& Lim, TK 2016, 'Severe community-acquired pneumonia: timely management measures in the first 24 hours', Critical Care, vol. 20, no. 1, pp. 237.

Rudan, I, O'brien, KL, Nair, H, Liu, L, Theodoratou, E, Qazi, S \& Child Health Epidemiology Reference Group 2013, 'Epidemiology and etiology of childhood pneumonia in 2010: estimates of incidence, severe morbidity, mortality, underlying risk factors and causative pathogens for 192 countries', Journal of Global Health, vol. 3, no. 1.

Schouten, LR, Veltkamp, F, Bos, AP, van Woensel, JB, Neto, AS, Schultz, MJ \& Wösten-van Asperen, RM 2016, 'Incidence and mortality of acute respiratory distress syndrome in children: a systematic review and metaanalysis', Critical Care Medicine, vol. 44, no. 4, pp. 819-829. Schuetz, P, Albrich, W \& Mueller, B 2011, 'Procalcitonin for diagnosis of infection and guide to antibiotic decisions: past, present and future', BMC Medicine, vol. 9, no. 1, pp. 107.

Schuetz, P, Christ-Crain, M, Thomann, R, Falconnier, C, Wolbers, M, Widmer, I \& Regez, K 2009, 'Effect of procalcitonin-based guidelines vs standard guidelines on antibiotic use in lower respiratory tract infections: the ProHOSP randomized controlled trial', The Journal of the American Medical Association, vol. 302, no. 10, pp. 10591066.

Schwarz, NG, Sarpong, N, Hünger, F, Marks, F, Acquah, SE, Agyekum, A \& Dekker, D 2010, 'Systemic bacteraemia in children presenting with clinical pneumonia and the impact of non-typhoid salmonella (NTS)', BMC Infectious Diseases, vol. 10, no. 1, pp. 319.

Self, WH, Rosen, J, Sharp, SC, Filbin, MR, Hou, PC, Parekh, AD, Kurz, MC \& Shapiro, N 2017, 'Diagnostic accuracy of FebriDx: a rapid test to detect immune responses to viral and bacterial upper respiratory infections', Journal of Clinical Medicine, vol. 6, no. 10, pp. 94.

Slinger, R, Hyde, L, Moldovan, I, Chan, F \& Pernica, JM 2014, 'Direct Streptococcus pneumoniae real-time PCR serotyping from pediatric parapneumonic effusions', BMC Pediatrics, vol. 14, no. 1, pp. 189.

Stein, RT, Bont, LJ, Zar, H, Polack, FP, Park, C, Claxton, A \& Wegzyn, C 2017, 'Respiratory syncytial virus hospitalization and mortality: systematic review and meta - analysis', Pediatric Pulmonology, vol. 52, no. 4, pp. 556-569.

Tate, JE, Burton, AH, Boschi-Pinto, C, Parashar, UD, World Health Organization-Coordinated Global Rotavirus Surveillance Network, Agocs, M, Serhan, F, de Oliveira, L, Mwenda, JM, Mihigo, R, Ranjan \& Wijesinghe, P 'Global, regional, and national estimates of rotavirus mortality in 
children $<5$ years of age, 2000-2013, Clinical Infectious Diseases, vol. 62(suppl_2), pp. 96-105.

Ten, Oever, J, Netea, MG \& Kullberg, BJ 2016, 'Utility of immune response-derived biomarkers in the differential diagnosis of inflammatory disorders', Journal of Infection, vol. 72, no. 1, pp. 1-18.

Turner, C, Turner, P, Carrara, V, Burgoine, K, Htoo, STL, Watthanaworawit, W \& Nosten, F 2013, 'High rates of pneumonia in children under two years of age in a South East Asian refugee population', PloS One, vol. 8, no. 1, pp. 54026.

UNICEF WHO 2019, Pneumonia the deadliest diseases for the world's poorest children, New York: UNICEF, <https://www.who.int/news-room/factsheets/detail/pneumonia>.

Varon, F, Torres-Caro, C, Herrera-Diaz, C, Ali, A, HernándezParra, A, Aguirre-Franco, C \& Uribe-Hernández, AM 2019, 'Microbiological characterization of severe exacerbations in Chronic Obstructive Pulmonary Disease (COPD) in patients admitted to the ICU with or without associated pneumonia: a retrospective cross-sectional study', Infection, vol. 23, no. 4, pp. 307-312.

Vogelmeier, CF, Criner, GJ, Martinez, FJ, Anzueto, A, Barnes, PJ, Bourbeau, J \& Frith, P 2017, 'Global strategy for the diagnosis, management, and prevention of chronic obstructive lung disease 2017 report. GOLD executive summary', American Journal of Respiratory and Critical Care Medicine, vol. 195, no. 5, pp. 557-582.

Wiersinga, WJ, Bonten, MJ, Boersma, WG, Jonkers, RE, Aleva, RM, Kullberg, BJ \& Sachs, APE 2018, 'Management of community-acquired pneumonia in adults: 2016 guideline update from the Dutch Working Party on Antibiotic Policy (SWAB) and Dutch Association of Chest Physicians (NVALT)', Netherlands Journal of Medicine, vol. 76 , no. 1 , pp. 4-13. 